\title{
Can the Lateral Habenula Crack the Serotonin Code?
}

\author{
Anna Tchenio ${ }^{1,2,3 \dagger}$, Kristina Valentinova ${ }^{1,2,3 \dagger}$ and Manuel Mameli ${ }^{1,2,3 *}$ \\ ${ }^{1}$ Institut du Fer à Moulin, Paris, France, ${ }^{2}$ Institut National de la Santé et de la Recherche Médicale (INSERM), UMR-S 839, \\ Paris, France, ${ }^{3}$ Université Pierre et Marie Curie, Paris, France
}

The lateral habenula $(\mathrm{LH} b)$ and the serotonergic system both contribute to motivational states by encoding rewarding and aversive signals. Converging evidence suggests that perturbation of these systems is critical for the pathophysiology of mood disorders. Anatomical and functional studies indicate that the serotonergic system and the $\mathrm{LHb}$ are interconnected in a forward-feedback loop. However, how serotonin release modifies the synaptic and cellular properties of LHb neurons and whether this has any behavioral repercussions remain poorly investigated. In this review article, we discuss insights gained from rodents and humans regarding the implications of the serotonin system and the LHb in aversion encoding and related disorders. We then describe the type, properties and pharmacology of serotonergic receptors expressed throughout the LHb. Finally, we discuss physiological data reporting how serotonergic signaling modifies synaptic transmission and neuronal activity within the LHb. Altogether, we combine a mechanistic- and circuit-level

\section{OPEN ACCESS}

Edited by:

Huib Mansvelder,

Vrije Universiteit Amsterdam

Netherlands

Reviewed by:

Dan McGehee,

University of Chicago, USA

Rodrigo Andrade,

Wayne State University School

of Medicine, USA

*Correspondence:

Manuel Mameli

manuel.mameli@inserm.fr

these authors have contributed equally to this work.

Received: 27 May 2016 Accepted: 04 October 2016 Published: 24 October 2016

Citation:

Tchenio A, Valentinova $K$ and Mameli M (2016) Can the Lateral Habenula Crack the Serotonin Code?

Front. Synaptic Neurosci. 8:34. doi: 10.3389/fnsyn.2016.00034 knowledge to provide an overview on how the LHb integrates serotonergic signals, a process potentially contributing to LHb-dependent encoding of valenced external stimuli.

Keywords: 5-HT, lateral habenula (LHb), synapses, raphe nuclei, neuromodulation

\section{INTRODUCTION}

The lateral habenula (LHb) bidirectionally connects with neuromodulatory centers, including the serotonergic raphe and dopaminergic midbrain nuclei (Wang and Aghajanian, 1977; Christoph et al., 1986; Varga et al., 2003; Hikosaka, 2010). Functional evidence from non-human primates indicates that LHb neurons encode external aversive and rewarding experiences (Matsumoto and Hikosaka, 2007). Furthermore, experimental results from humans and rodents suggest that $\mathrm{LHb}$ neuronal hyperactivity may represent a cellular substrate underlying depressive-like symptoms in mood disorders and drug addiction (Sartorius et al., 2010; Shabel et al., 2014; Meye et al., 2015, 2016; Lecca et al., 2016). Altogether, this indicates that the LHb represents a major anatomical substrate, processing valenced stimuli in physiological and pathological conditions.

The serotonergic system also participates in the processing of motivation (Faulkner and Deakin, 2014). A wealth of literature supports the idea that its perturbation contributes to drug addiction (Müller and Homberg, 2015) and, importantly, to the etiology of mood disorders (Cannon et al., 2007). However, whether serotonin-dependent modulation of LHb shapes motivational states remains elusive. Here, we will first describe the anatomical and functional relevance of serotonergic signaling within the LHb. Next, we will discuss the potential significance of serotonin control on $\mathrm{LHb}$ function for behaviors associated with motivation and related disorders. 


\section{LHb PROCESSING OF REWARD AND AVERSION}

The LHb is located in the epithalamus, underneath the third ventricle and above the posterior end of the thalamus. It includes a medial and a lateral division, which are anatomically distinct, receive specific innervation and can encode aversive behaviors (Andres et al., 1999; Shabel et al., 2012; Stamatakis et al., 2016). Indeed, anterograde and optogenetic studies demonstrated that afferents from the entopeduncular nucleus (EPN), the ventral tegmental area or the lateral hypothalamus innervate different territories, and drive aversive behaviors (Shabel et al., 2012; Root et al., 2014; Stamatakis et al., 2016). Neurons located in the LHb are predominantly of glutamatergic type and although morphologically diverse, they are present as simple dendritic arborization and postsynaptic spines (Weiss and Veh, 2011; Maroteaux and Mameli, 2012). Despite this general homogeneous phenotype, LHb neurons present a heterogeneous expression of neuropeptides and proteins, indicating that distinct habenular neuronal subpopulations may serve different biological functions (Geisler et al., 2003; Weiss and Veh, 2011; Aizawa et al., 2012; Proulx et al., 2014). However, the significance of each $\mathrm{LHb}$ neuronal subpopulation remains obscure. If a cytochemical identification of $\mathrm{LHb}$ neurons exists, the development of genetic tools can allow to discriminate and test the significance of each individual $\mathrm{LHb}$ neuronal subtype allowing to refine our knowledge on LHb function.

Glutamatergic projections from the LHb descend through the fasciculus retroflexus and make synapses with neuronal populations in deep structures: GABAergic and dopaminergic neurons in the midbrain and GABAergic and serotonergic neurons in the dorsal and median raphe (DRN and MRN respectively; Wang and Aghajanian, 1977; Stern et al., 1979; Lammel et al., 2012; Stamatakis and Stuber, 2012; Pollak Dorocic et al., 2014).

Seminal studies in behaving monkeys initially described that neuronal activity in the LHb contributes to the processing of aversive and rewarding stimuli (Matsumoto and Hikosaka, 2007). Indeed, the activity of LHb neurons increases when an airpuff (aversive stimulus) is presented in an unexpected fashion. After a series of conditioning sessions, the firing of $\mathrm{LHb}$ neurons increases following a cue predicting the aversive stimulus onset. Conversely, the unexpected delivery of rewards, and cues predicting them decreases LHb neuronal firing (Matsumoto and Hikosaka, 2007, 2009). This role of the LHb in processing negative stimuli and "anti-reward" signals is further supported by studies employing optogenetic approaches. LHb infusion with viral vectors encoding for excitatory opsins allows to probe the behavioral importance of LHb output onto afferent midbrain nuclei. Optical stimulation of LHb terminals leads to avoidance behaviors (Lammel et al., 2012; Stamatakis and Stuber, 2012). These findings support the idea that activation of the LHb is sufficient for driving negative motivational states.

However, whether neuromodulators gate this LHb-mediated behavior remains poorly studied. In this review article, we will focus on the role of serotonin-dependent neuromodulation within the LHb.

\section{BIDIRECTIONAL CONNECTIVITY BETWEEN RAPHE AND LHb}

Neuroanatomical tracing studies reported a direct projection from LHb neurons to both DRN and MRN, as well as an indirect projection via the GABAergic rostromedial tegmental nucleus located in the midbrain (Wang and Aghajanian, 1977; Jhou et al., 2009; Bernard and Veh, 2012; Quina et al., 2015). LHb neurons sending axons to the raphe are mainly located in the medial territory of the LHb. Moreover, axons from the LHb more prominently target the MRN compared to the DRN (Bernard and Veh, 2012; Quina et al., 2015). However, the above-mentioned tracing studies did not differentiate the targeted neuronal subtype within the raphe. Recent studies employed rabies-based viral strategy and Cre-driver mouse lines to identify that LHb neurons make synapses onto DRN/MRN serotonergic neurons and DRN GABA neurons (Pollak Dorocic et al., 2014; Weissbourd et al., 2014).

Importantly, also raphe neurons send axons to the LHb. Tracing approaches using phalloidin anterograde labeling indicate the presence of MRN and DRN fibers throughout the whole LHb (Vertes, 1991; Vertes et al., 1999). One of the limitations of this analysis is the lack of information regarding cell-type specificity of the raphe neurons projecting onto the LHb. Using transgenic mice expressing Cre-recombinase in Sert-positive raphe neurons provided evidence that serotonin cells in the DRN send a prominent axonal innervation to the lateral portion of the LHb (Morin and Meyer-Bernstein, 1999; Muzerelle et al., 2016), in line with the presynaptic expression of serotonin and its transporter in the LHb (Kiyasova et al., 2011). This is in stark contrast with other immunolabeling studies indicating the terminal expression of Sert or serotonin itself in the medial portion of the LHb (Geisler et al., 2003; Zhang et al., 2016). The combinatorial use of genetic tools, optogenetic strategies and electrophysiology will be necessary to refine our understanding of the LHb-Raphe-LHb connectivity.

\section{SEROTONIN RECEPTOR EXPRESSION WITHIN THE LHb}

Serotonin can activate 14 subtypes of receptors, which belong to seven families according to their pharmacological and molecular properties (Barnes and Sharp, 1999). The signaling pathways of the different isoforms have been extensively described (Hoyer et al., 1994). In summary, with the exception of 5-HT3 which is a ligand-gated cation channel, all the 5-HT receptors are G-coupled proteins (Millan et al., 2008). 5-HT1 (5-HT1A-F) and 5-HT5A receptors are predominantly coupled to $\mathrm{G}_{\mathrm{i} / \mathrm{o}}$ proteins, which can inhibit cyclic AMP, open $\mathrm{K}^{+}$or close $\mathrm{Ca}^{2+}$ channels. 5-HT2 receptors (5-HT2A-C) couple to $G_{q}$ proteins and increase the Inositol-3-phosphate hydrolysis leading to diacylglycerol generation. 5-HT4, 5-HT6 and 5-HT7, instead, are $\mathrm{G}_{\mathrm{s}}$-coupled proteins and act to increase 
cyclic AMP levels. 5HT receptors, depending on the subtype and anatomical localization, can be pre- or postsynaptically expressed, thereby regulating presynaptic neurotransmitter release or postsynaptic cell function, respectively (Barnes and Sharp, 1999).

Several subtypes of 5- $\mathrm{HT}$ receptors are expressed in the LHb including the 5-HT1B, 5-HT2C, 5-HT7 and 5-HT5. In situ hybridization techniques revealed high labeling of 5-HT7 in the LHb at postnatal day 5 in the rat. However, this labeling decreased over time reaching a very low signal in the adult stage (Vizuete et al., 1997), indicative of a developmental regulation of this receptor subtype. While the 5-HT2A was not detected, a strong expression of 5-HT2C was found throughout the whole LHb (Pompeiano et al., 1994; Clemett et al., 2000). Accordingly, micro-array analysis also revealed 5-HT2C and 5-HT1B expression, the latter mainly localized in the medial part of the LHb (Wagner et al., 2016). Although 5HT receptor expression within the LHb has been widely assessed, their localization at the pre- or postsynaptic compartment, or their functional and behavioral significance remains less clear. Only recently, data obtained using electrophysiological approaches indicated that while the 5-HT2C is postsynaptically expressed, the 5 -HT1B is rather presynaptically located, providing the first insight on the physiological role of serotonin within the LHb (Hwang and Chung, 2014; Zuo et al., 2016).

\section{SEROTONIN-DRIVEN MODULATION OF SYNAPTIC TRANSMISSION IN THE LHb}

Serotonin release modulates glutamatergic and GABAergic synaptic transmission throughout the central nervous system by acting on its specific receptors (Maejima et al., 2013). Recent evidence indicates that serotonin modulates excitatory and inhibitory synaptic currents onto LHb neurons. An initial set of experiments made use of the expression of Channelrhodopsin-2 in the EPN of the basal ganglia. EPN neurons send axons capable to co-release glutamate and GABA to the lateral portion of the LHb (Shabel et al., 2012). Light-evoked excitatory and inhibitory postsynaptic currents (EPSCs and IPSCs, respectively) were reduced by continuous bath application of exogenous serotonin. The diminished amplitude of EPSCs and IPSCs occurred along with an increased paired pulse ratio, indicative of a presynaptic reduction in the probability of neurotransmitter release (Shabel et al., 2012, 2014). However the subtype of 5-HT receptor involved in this modulation, as well as its pre- or postsynaptic localization remains still unknown.

5-HT1B receptors are expressed in the LHb, are typically presynaptically located and most often control presynaptic neurotransmitter release (Lesch and Waider, 2012; Wagner et al., 2016). The activation of this receptor subtype may therefore underlie serotonin-dependent modulation of EPN-toLHb synapses. Accordingly, acute exposure of LHb-containing slices to the specific 5-HT1B receptor agonist CP93129 or to serotonin produced: (i) a long-lasting depression of evoked EPSCs; and (ii) a transient reduction of spontaneous EPSC frequency (Hwang and Chung, 2014; Xie et al., 2016). This effect was prevented by the 5-HT1B receptor antagonist SB216641. Notably, an agonist of the 5-HT1A receptors only transiently decreased EPSCs (Hwang and Chung, 2014). However, also this effect was blocked by the 5-HT1B antagonist, indicating either a cross-talk between receptor subtypes or alternatively a non-specific effect (i.e., concentration dependent) of these compounds (Table 1). This form of plasticity was presynaptically expressed, and required nitric oxide and ryanodine receptor-dependent $\mathrm{Ca}^{2+}$ release. Importantly, no modifications were observed postsynaptically, as serotonin failed to change AMPA receptor-mediated responses triggered by direct AMPA application (Hwang and Chung, 2014). Whether the reported serotonin-dependent reduction at EPNto-LHb synapse requires similar mechanisms remains to be established. This work highlights important issues regarding the pharmacology of $5 \mathrm{HT}$, suggesting that the results obtained to date using synthetic compounds should be carefully interpreted given the complex pharmacology of 5HT receptors (Table 1 and Figure 1). Conditional deletion or the use of CRISPRCas9 technology to downregulate specific 5HT receptors may represent an alternative approach to provide more precise and informative insights on the type of receptors governing $\mathrm{LHb}$ synaptic function (Shalem et al., 2015).

In most cells, however, spontaneous glutamate mediated synaptic activity onto LHb neurons was facilitated by serotonin. This effect occurred via increased presynaptic glutamate release through 5-HT2 and 5-HT3 receptor activation (Xie et al., 2016). However, insights about the input-specific expression and

TABLE 1 | Pharmacological effects of 5-HT receptor agonists and antagonists on the synaptic properties of Lateral habenula (LHb) neurons.

\begin{tabular}{|c|c|c|c|c|c|}
\hline Receptor & Agonist & Effect in LHb & Antagonist & Effect in LHb & References \\
\hline $5-\mathrm{HT} 1$ & $5-\mathrm{CT}$ & Reduction of EPSCs & Cyanopindolol & Blocks EPSC reduction & Hwang and Chung (2014) \\
\hline 5-HT1B & CP93129 & Reduction of EPSCs & SB216641 & Blocks EPSC reduction & Hwang and Chung (2014) \\
\hline \multirow[t]{2}{*}{ 5-HT2A-C } & $\alpha$-methyl 5HT & $\begin{array}{l}\text { High dose: } \downarrow \text { EPSCs; } \\
\text { low dose: } \uparrow \text { EPSCs }\end{array}$ & Ritanserin & $\begin{array}{l}\text { Blocks the } \uparrow \text { of EPSCs } \\
\text { induced by a low dose of } \\
\alpha \text {-methyl } 5 \mathrm{HT}\end{array}$ & Hwang and Chung (2014) \\
\hline & mCPP & $\begin{array}{l}\text { Slow inward current; } \\
\uparrow \text { frequency of sEPSCs } \\
\uparrow \text { firing rate }\end{array}$ & $\begin{array}{l}\text { Ritanserin } \\
\text { SB200646 }\end{array}$ & Attenuates effects of $5 \mathrm{HT}$ & $\begin{array}{l}\text { Xie et al. (2016) } \\
\text { and Zuo et al. (2016) }\end{array}$ \\
\hline $5-\mathrm{HT} 3$ & mCPBG & $\begin{array}{l}\text { Slow inward current; } \\
\uparrow \text { firing rate }\end{array}$ & OND & Attenuates effects of $5 \mathrm{HT}$ & $\begin{array}{l}\text { Xie et al. (2016) } \\
\text { and Zuo et al. (2016) }\end{array}$ \\
\hline
\end{tabular}



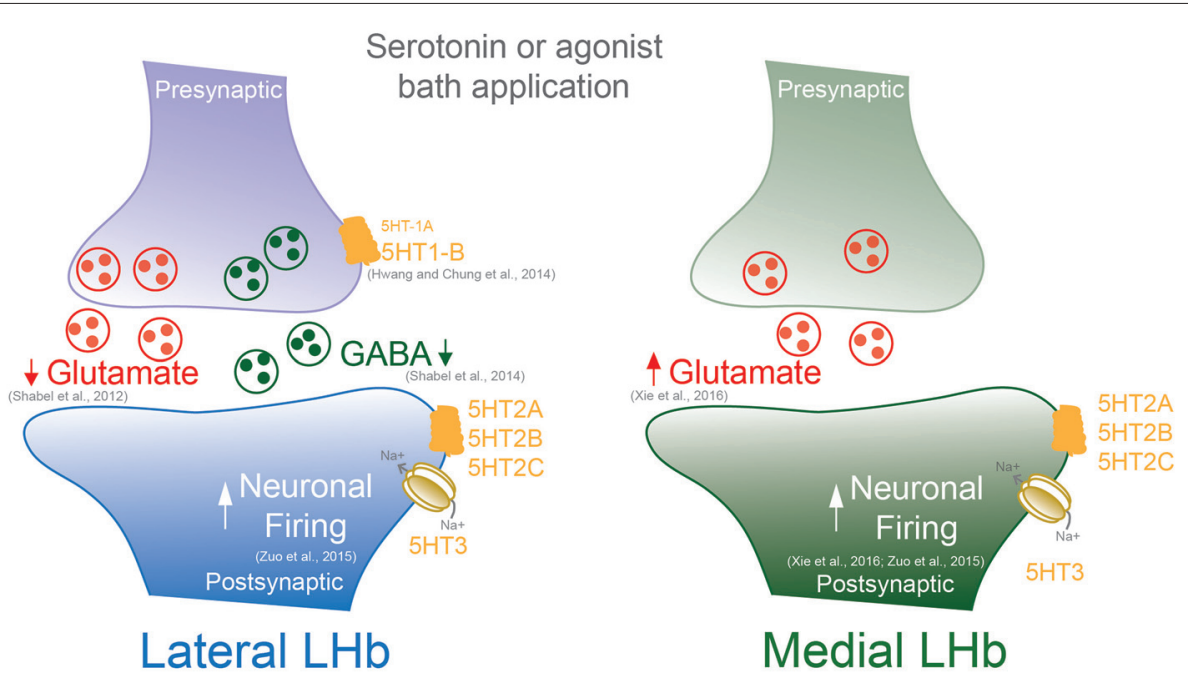

FIGURE 1 | Serotonin or specific bath application of 5-HT agonists modifies presynaptic and postsynaptic neurotransmission in both the medial and lateral portion of the Lateral habenula (LHb).

subcellular localization of these receptors are still lacking and require further investigation. Future studies would need to provide or rule out whether LHb neurons located in the medial or lateral territory express different 5 -HT receptor subtypes. These findings would be relevant to better understand the serotonindependent bidirectional control of LHb synaptic transmission.

Unlike excitatory transmission, much less is known about the serotonin-dependent modulation of GABAergic transmission in the LHb. Serotonin application decreased optogeneticallydriven EPN-to-LHb IPSCs, and IPSCs evoked by extracellular stimulation (Hwang and Chung, 2014; Shabel et al., 2014). On the other hand, a chronic treatment with serotonin transporter inhibitors (SSRI), which typically elevates extracellular serotonin concentration, led to increased GABA/AMPA ratios and presynaptic GABA markers at EPN-to-LHb synapses (Shabel et al., 2014). This discrepancy might be due to the differential effect and adaptations that may occur between the acute activation of the receptors vs. the long-term changes triggered by the chronic SSRI treatment. Furthermore, it remains unclear whether the SSRI-dependent synaptic plasticity results from the direct serotonin modulation within the $\mathrm{LHb}$ or rather from wider circuit adaptations. These results set the stage for further investigation on the mechanisms underlying the serotonin-dependent synapse-specific plasticity in the LHb. An in-depth understanding of serotonin-dependent changes in synaptic transmission would allow to decipher their behavioral relevance and to assess their contribution to motivated behaviors or pathologies where this encoding is disrupted.

\section{SEROTONIN MODIFIES OUTPUT FIRING OF LHb NEURONS}

What could be the functional repercussions of serotonin release on LHb activity? Bath application of serotonin in rat brain slices induced a marked depolarization in the majority of LHb neurons.
This effect was independent from synaptic neurotransmitter release as it was insensitive to tetrodotoxin and synaptic receptor antagonists. These effects on the membrane potential occurred along with an increase in LHb spontaneous neuronal firing. Serotonin-dependent increase of activity was more pronounced in cells recorded in the lateral division of the LHb (Zuo et al., 2016). This is in line with the reported predominant DRN input onto the lateral portion of the LHb (Muzerelle et al., 2016). Serotonin actions on the membrane potential and on LHb neuronal firing was mediated by postsynaptically expressed 5-HT2/3 receptors (Zuo et al., 2016). The effect of serotonin was dependent on transient receptor potential channels (TRP) and $\mathrm{Ca}^{2+}$ signaling, however a clear link between the 5HT receptors and its intracellular signaling remains unknown (Zuo et al., 2016). Moreover, increasing endogenous serotonin concentrations by Sert blockade induced a depolarizing current and increased the firing rate of LHb neurons, mimicking the effect of exogenous serotonin (Zuo et al., 2016; Figure 1).

Single unit recordings in anesthetized rodents indicate that a functional connection exists between the DRN and the LHb (Andersen et al., 1983; Dong et al., 1992). Indeed, local activation of the 5-HT2C receptors within the LHb transiently increased $\mathrm{LHb}$ spontaneous firing rate and bursting activity (Han et al., 2015). On the other hand, 5-HT1B receptor activation decreased serotonin release in the LHb as measured by microdialysis methods (Adell et al., 2001). This supports the above-described evidence for a presynaptic 5-HT1B receptor expression, and suggests a presynaptic modulation of serotonin release. Whether specific DRN-driven serotonin release occurs in the LHb, and whether this modulates $\mathrm{LHb}$ neuronal function remains to be explored.

Altogether, this evidence indicates the importance of serotonin in the modulation of LHb neuronal activity. Considering that the major effect exerted by serotonin is an increase in neuronal firing, serotonin release may therefore 
trigger avoidance or pathological states such as depressive symptoms characterized by LHb hyperactivity (Lecca et al., 2014).

\section{CONCLUDING REMARKS}

That the LHb and the serotonergic system are anatomically interconnected is known since decades. However, the functional implications of this connectivity, and the specific modulation of synaptic transmission by serotonin release remain understudied. The combination of optogenetics with pharmacology and electrophysiology has recently revealed that serotonergic signaling influences the activity of LHb neurons, as well as synaptic neurotransmission. Despite this evidence, the function, subterritorial expression and behavioral relevance of discrete 5 -HT receptors within the $\mathrm{LHb}$ remain vague. This is partly hampered by the limitation in mimicking of physiological serotonin release and its consequences on $\mathrm{LHb}$ function. Indeed, the data so far rely on receptor pharmacology in acute brain slices. Future research needs to tackle the role of 5-HT receptors by employing genetic strategies, as well as electrochemistry or for instance by pushing the bioengineering of 5-HT receptors that would be activated by synthetic drugs or light.

While we have discussed the anatomical connections underlying serotonergic signals within the $\mathrm{LHb}$, it remains unknown when and how serotonin release occurs in the LHb. The use of approaches assessing neuronal activity in vivo may represent a strategy to circumvent this problem.

The activity of serotonin neurons regulates a wealth of brain functions including emotions, appetitive and aversive stimuli or aggression (Audero et al., 2013; Hayashi et al., 2015; Teissier et al., 2015). Furthermore, perturbation of serotonin neurons firing

\section{REFERENCES}

Adell, A., Celada, P., and Artigas, F. (2001). The role of 5-HT1B receptors in the regulation of serotonin cell firing and release in the rat brain. J. Neurochem. 79, 172-182. doi: 10.1046/j.1471-4159.2001.00550.x

Aizawa, H., Kobayashi, M., Tanaka, S., Fukai, T., and Okamoto, H. (2012). Molecular characterization of the subnuclei in rat habenula. J. Comp. Neurol. 520, 4051-4066. doi: 10.1002/cne.23167

Andersen, E., Rigor, B., and Dafny, N. (1983). Electrophysiological evidence of concurrent dorsal raphe input to caudate, septum, habenula, thalamus hippocampus, cerebellum and olfactory bulb. Int. J. Neurosci. 18, 107-115. doi: 10.3109/00207458308985884

Andres, K. H., von Düring, M., and Veh, R. W. (1999). Subnuclear organization of the rat habenular complexes. J. Comp. Neurol. 407, 130-150. doi: 10 . 1002/(SICI)1096-9861(19990428)407:1<130::AID-CNE10>3.0.CO;2-8

Audero, E., Mlinar, B., Baccini, G., Skachokova, Z. K., Corradetti, R., and Gross, C. (2013). Suppression of serotonin neuron firing increases aggression in mice. J. Neurosci. 33, 8678-8688. doi: 10.1523/JNEUROSCI.2067-12.2013

Barnes, N. M., and Sharp, T. (1999). A review of central 5-HT receptors and their function. Neuropharmacology 38, 1083-1152. doi: 10.1016/s00283908(99)00010-6

Bernard, R., and Veh, R. W. (2012). Individual neurons in the rat lateral habenular complex project mostly to the dopaminergic ventral tegmental area or to the serotonergic raphe nuclei. J. Comp. Neurol. 520, 2545-2558. doi: 10.1002/cne. 23080

Blier, P., and El Mansari, M. (2013). Serotonin and beyond: therapeutics for major depression. Philos. Trans. R. Soc. Lond. B Biol. Sci. 368:20120536. doi: 10. 1098/rstb.2012.0536 and thereby serotonin release contributes to pathological states such as neuropathic pain, anxiety, mood disorders and addiction (Müller et al., 2007; Blier and El Mansari, 2013; Sagheddu et al., 2015). It is plausible that serotonin-dependent modulation of LHb neurotransmission may contribute to serotonin-driven behaviors in physiological conditions and pathologies that are characterized by aberrant LHb activity (Li et al., 2011; Meye et al., 2015; Lecca et al., 2016). It would be important to understand the relevance of the reciprocal connection of LHb-Raphe-LHb, and the repercussions onto specific $\mathrm{LHb}$ downstream systems, such as the dopamine system, a key player in motivational processing. A major effort on these topics would allow a better understanding of the role of serotonin in encoding aversive and rewarding stimuli. It may furthermore help to decipher the maladaptive mechanisms taking place in neuropsychiatric disorders characterized by perturbation of $\mathrm{LHb}$ and serotonin system function.

\section{AUTHOR CONTRIBUTIONS}

MM, AT and KV together contributed to the conceptualization of the manuscript and wrote the manuscript.

\section{ACKNOWLEDGMENTS}

We thank the entire Mameli laboratory for discussions and S. Lecca and M. Trusel for comments on the manuscript. This work is supported by the City of Paris, European Research Council Starting Grant SalienSy 335333 (MM). The Mameli laboratory is part of the LabEx BioPsy Network. KV is supported by a doctoral fellowship from the French Ministry of Education (MESR).

Cannon, D. M., Ichise, M., Rollis, D., Klaver, J. M., Gandhi, S. K., Charney, D. S., et al. (2007). Elevated serotonin transporter binding in major depressive disorder assessed using positron emission tomography and $\left[{ }^{11} \mathrm{C}\right] \mathrm{DASB}$; comparison with bipolar disorder. Biol. Psychiatry 62, 870-877. doi: 10.1016/j. biopsych.2007.03.016

Christoph, G. R., Leonzio, R. J., and Wilcox, K. S. (1986). Stimulation of the lateral habenula inhibits dopamine-containing neurons in the substantia nigra and ventral tegmental area of the rat. J. Neurosci. 6, 613-619.

Clemett, D. A., Punhani, T., Duxon, M. S., Blackburn, T. P., and Fone, K. C. (2000). Immunohistochemical localisation of the $5-\mathrm{HT}_{2 \mathrm{C}}$ receptor protein in the rat CNS. Neuropharmacology 39, 123-132. doi: 10.1016/s0028-3908(99) 00086-6

Dong, W. Q., Wilson, O. B., Skolnick, M. H., and Dafny, N. (1992). Hypothalamic, dorsal raphe and external electrical stimulation modulate noxious evoked responses of habenula neurons. Neuroscience 48, 933-940. doi: 10.1016/03064522(92)90281-6

Faulkner, P., and Deakin, J. F. (2014). The role of serotonin in reward, punishment and behavioural inhibition in humans: insights from studies with acute tryptophan depletion. Neurosci. Biobehav. Rev. 46, 365-378. doi: 10.1016/j. neubiorev.2014.07.024

Geisler, S., Andres, K. H., and Veh, R. W. (2003). Morphologic and cytochemical criteria for the identification and delineation of individual subnuclei within the lateral habenular complex of the rat. J. Comp. Neurol. 458, 78-97. doi: 10. 1002/cne.10566

Han, L. N., Zhang, L., Li, L. B., Sun, Y. N., Wang, Y., Chen, L., et al. (2015). Activation of serotonin $2 C$ receptors in the lateral habenular nucleus increases the expression of depression-related behaviors in the hemiparkinsonian rat. Neuropharmacology 93, 68-79. doi: 10.1016/j.neuropharm.2015.01.024 
Hayashi, K., Nakao, K., and Nakamura, K. (2015). Appetitive and aversive information coding in the primate dorsal raphé nucleus. J. Neurosci. 35, 6195-6208. doi: 10.1523/JNEUROSCI.2860-14.2015

Hikosaka, O. (2010). The habenula: from stress evasion to value-based decisionmaking. Nat. Rev. Neurosci. 11, 503-513. doi: 10.1038/nrn2866

Hoyer, D., Clarke, D. E., Fozard, J. R., Hartig, P. R., Martin, G. R., Mylecharane, E. J., et al. (1994). International union of pharmacology classification of receptors for 5-hydroxytryptamine (Serotonin). Pharmacol. Rev. 46, 157-203.

Hwang, E. K., and Chung, J. M. (2014). $5 \mathrm{HT}_{1 \mathrm{~B}}$ receptor-mediated pre-synaptic depression of excitatory inputs to the rat lateral habenula. Neuropharmacology 81, 153-165. doi: 10.1016/j.neuropharm.2014.01.046

Jhou, T. C., Geisler, S., Marinelli, M., Degarmo, B. A., and Zahm, D. S. (2009). The mesopontine rostromedial tegmental nucleus: a structure targeted by the lateral habenula that projects to the ventral tegmental area of tsai and substantia nigra compacta. J. Comp. Neurol. 513, 566-596. doi: 10.1002/cne.21891

Kiyasova, V., Fernandez, S. P., Laine, J., Stankovski, L., Muzerelle, A., Doly, S., et al. (2011). A genetically defined morphologically and functionally unique subset of 5-HT neurons in the mouse raphe nuclei. J. Neurosci. 31, 2756-2768. doi: 10. 1523/JNEUROSCI.4080-10.2011

Lammel, S., Lim, B. K., Ran, C., Huang, K. W., Betley, M. J., Tye, K. M., et al. (2012). Input-specific control of reward and aversion in the ventral tegmental area. Nature 491, 212-217. doi: 10.1038/nature11527

Lecca, S., Meye, F. J., and Mameli, M. (2014). The lateral habenula in addiction and depression: an anatomical, synaptic and behavioral overview. Eur. J. Neurosci. 39, 1170-1178. doi: 10.1111/ejn.12480

Lecca, S., Pelosi, A., Tchenio, A., Moutkine, I., Lujan, R., Hervé, D., et al. (2016). Rescue of GABAB and GIRK function in the lateral habenula by protein phosphatase $2 \mathrm{~A}$ inhibition ameliorates depression-like phenotypes in mice. Nat. Med. 22, 254-261. doi: 10.1038/nm.4037

Lesch, K. P., and Waider, J. (2012). Serotonin in the modulation of neural plasticity and networks: implications for neurodevelopmental disorders. Neuron 76, 175-191. doi: 10.1016/j.neuron.2012.09.013

Li, B., Piriz, J., Mirrione, M., Chung, C., Proulx, C. D., Schulz, D., et al. (2011). Synaptic potentiation onto habenula neurons in the learned helplessness model of depression. Nature 470, 535-539. doi: 10.1038/nature09742

Maejima, T., Masseck, O. A., Mark, M. D., and Herlitze, S. (2013). Modulation of firing and synaptic transmission of serotonergic neurons by intrinsic $\mathrm{G}$ proteincoupled receptors and ion channels. Front. Integr. Neurosci. 7:40. doi: 10. 3389/fnint.2013.00040

Maroteaux, M., and Mameli, M. (2012). Cocaine evokes projection-specific synaptic plasticity of lateral habenula neurons. J. Neurosci. 32, 12641-12646. doi: 10.1523/JNEUROSCI.2405-12.2012

Matsumoto, M., and Hikosaka, O. (2007). Lateral habenula as a source of negative reward signals in dopamine neurons. Nature 447, 1111-1115. doi: 10 . 1038/nature 05860

Matsumoto, M., and Hikosaka, O. (2009). Representation of negative motivational value in the primate lateral habenula. Nat. Neurosci. 12, 77-84. doi: 10.1038/nn. 2233

Meye, F. J., Soiza-Reilly, M., Smit, T., Diana, M. A., Schwarz, M., and Mameli, M. (2016). Shifted pallidal co-release of GABA and glutamate in habenula drives cocaine withdrawal and relapse. Nat. Neurosci. 19, 1019-1024. doi: 10.1038/nn. 4334

Meye, F. J., Valentinova, K., Lecca, S., Marion-Poll, L., Maroteaux, M. J., Musardo, S., et al. (2015). Cocaine-evoked negative symptoms require AMPA receptor trafficking in the lateral habenula. Nat. Neurosci. 18, 376-378. doi: 10. 1038/nn.3923

Millan, M. J., Marin, P., Bockaert, J., and Mannoury la Cour, C. (2008). Signaling at G-protein-coupled serotonin receptors: recent advances and future research directions. Trends Pharmacol. Sci. 29, 454-464. doi: 10.1016/j.tips.2008.06.007

Morin, L. P., and Meyer-Bernstein, E. L. (1999). The ascending serotonergic system in the hamster: comparison with projections of the dorsal and median raphe nuclei. Neuroscience 91, 81-105. doi: 10.1016/s0306-4522(98) 00585-5

Müller, C. P., Carey, R. J., Huston, J. P., and De Souza Silva, M. A. (2007). Serotonin and psychostimulant addiction: focus on $5-\mathrm{HT}_{1 A}$-receptors. Prog. Neurobiol. 81, 133-178. doi: 10.1016/j.pneurobio.2007.01.001

Müller, C. P., and Homberg, J. R. (2015). The role of serotonin in drug use and addiction. Behav. Brain Res. 277, 146-192. doi: 10.1016/j.bbr.2014.04.007
Muzerelle, A., Scotto-Lomassese, S., Bernard, J. F., Soiza-Reilly, M., and Gaspar, P. (2016). Conditional anterograde tracing reveals distinct targeting of individual serotonin cell groups (B5-B9) to the forebrain and brainstem. Brain Struct. Funct. 221, 535-561. doi: 10.1007/s00429-014-0924-4

Pollak Dorocic, I., Fürth, D., Xuan, Y., Johansson, Y., Pozzi, L., Silberberg, G., et al. (2014). A whole-brain atlas of inputs to serotonergic neurons of the dorsal and median raphe nuclei. Neuron 83, 663-678. doi: 10.1016/j.neuron.2014. 07.002

Pompeiano, M., Palacios, J. M., and Mengod, G. (1994). Distribution of the serotonin $5-\mathrm{HT}_{2}$ receptor family mRNAs: comparison between $5-\mathrm{HT}_{2 A}$ and 5- $\mathrm{HT}_{2 \mathrm{C}}$ receptors. Mol. Brain Res. 23, 163-178. doi: 10.1016/0169328x(94)90223-2

Proulx, C. D., Hikosaka, O., and Malinow, R. (2014). Reward processing by the lateral habenula in normal and depressive behaviors. Nat. Neurosci. 17, 1146-1152. doi: 10.1038/nn.3779

Quina, L. A., Tempest, L., Ng, L., Harris, J. A., Ferguson, S., Jhou, T. C., et al. (2015). Efferent pathways of the mouse lateral habenula. J. Comp. Neurol. 523, 32-60. doi: 10.1002/cne.23662

Root, D. H., Mejias-Aponte, C. A., Qi, J., and Morales, M. (2014). Role of glutamatergic projections from ventral tegmental area to lateral habenula in aversive conditioning. J. Neurosci. 34, 13906-13910. doi: 10.1523/JNEUROSCI. 2029-14.2014

Sagheddu, C., Aroni, S., De Felice, M., Lecca, S., Luchicchi, A., Melis, M., et al. (2015). Enhanced serotonin and mesolimbic dopamine transmissions in a rat model of neuropathic pain. Neuropharmacology 97, 383-393. doi: 10.1016/j. neuropharm.2015.06.003

Sartorius, A., Kiening, K. L., Kirsch, P., von Gall, C. C., Haberkorn, U., Unterberg, A. W., et al. (2010). Remission of major depression under deep brain stimulation of the lateral habenula in a therapy-refractory patient. Biol. Psychiatry 67, e9-e11. doi: 10.1016/j.biopsych.2009.08.027

Shabel, S. J., Proulx, C. D., Piriz, J., and Malinow, R. (2014). Mood regulation. GABA/glutamate co-release controls habenula output and is modified by antidepressant treatment. Science 345, 1494-1498. doi: 10.1126/science. 1250469

Shabel, S. J., Proulx, C. D., Trias, A., Murphy, R. T., and Malinow, R. (2012). Input to the lateral habenula from the basal ganglia is excitatory, aversive and suppressed by serotonin. Neuron 74, 475-481. doi: 10.1016/j.neuron.2012. 02.037

Shalem, O., Sanjana, N. E., and Zhang, F. (2015). High-throughput functional genomics using CRISPR-Cas9. Nat. Rev. Genet. 16, 299-311. doi: 10. 1038/nrg3899

Stamatakis, A. M., and Stuber, G. D. (2012). Activation of lateral habenula inputs to the ventral midbrain promotes behavioral avoidance. Nat. Neurosci. 15, 1105-1107. doi: 10.1038/nn.3145

Stamatakis, A. M., Van Swieten, M., Basiri, M. L., Blair, G. A., Kantak, P., and Stuber, G. D. (2016). Lateral hypothalamic area glutamatergic neurons and their projections to the lateral habenula regulate feeding and reward. J. Neurosci. 36, 302-311. doi: 10.1523/JNEUROSCI.1202-15.2016

Stern, W. C., Johnson, A., Bronzino, J. D., and Morgane, P. J. (1979). Effects of electrical stimulation of the lateral habenula on single-unit activity of raphe neurons. Exp. Neurol. 65, 326-342. doi: 10.1016/0014-4886(79) 90102-x

Teissier, A., Chemiakine, A., Inbar, B., Bagchi, S., Ray, R. S., Palmiter, R. D., et al. (2015). Activity of raphé serotonergic neurons controls emotional behaviors. Cell Rep. 13, 1965-1976. doi: 10.1016/j.celrep.2015.10.061

Varga, V., Kocsis, B., and Sharp, T. (2003). Electrophysiological evidence for convergence of inputs from the medial prefrontal cortex and lateral habenula on single neurons in the dorsal raphe nucleus. Eur. J. Neurosci. 17, 280-286. doi: 10.1046/j.1460-9568.2003.02465.x

Vertes, R. P. (1991). A PHA-L analysis of ascending projections of the dorsal raphe nucleus in the rat. J. Comp. Neurol. 313, 643-668. doi: 10.1002/cne.9031 30409

Vertes, R. P., Fortin, W. J., and Crane, A. M. (1999). Projections of the median raphe nucleus in the rat. J. Comp. Neurol. 407, 555-582. doi: 10 1002/(SICI)1096-9861(19990517)407:4<555::AID-CNE7>3.0.CO;2-E

Vizuete, M. L., Venero, J. L., Traiffort, E., Vargas, C., Machado, A., and Cano, J. (1997). Expression of 5-HT7 receptor mRNA in rat brain during postnatal development. Neurosci. Lett. 227, 53-56. doi: 10.1016/s0304-3940(97) 00302-9 
Wagner, F., French, L., and Veh, R. W. (2016). Transcriptomic-anatomic analysis of the mouse habenula uncovers a high molecular heterogeneity among neurons in the lateral complex, while gene expression in the medial complex largely obeys subnuclear boundaries. Brain Struct. Funct. 221, 39-58. doi: 10. 1007/s00429-014-0891-9

Wang, R. Y., and Aghajanian, G. K. (1977). Physiological evidence for habenula as major link between forebrain and midbrain raphe. Science 197, 89-91. doi: 10. 1126/science. 194312

Weiss, T., and Veh, R. W. (2011). Morphological and electrophysiological characteristics of neurons within identified subnuclei of the lateral habenula in rat brain slices. Neuroscience 172, 74-93. doi: 10.1016/j.neuroscience.2010. 10.047

Weissbourd, B., Ren, J., DeLoach, K. E., Guenthner, C. J., Miyamichi, K., and Luo, L. (2014). Presynaptic partners of dorsal raphe serotonergic and GABAergic neurons. Neuron 83, 645-662. doi: 10.1016/j.neuron.2014. 06.024

Xie, G., Zuo, W., Wu, L., Li, W., Wu, W., Bekker, A., et al. (2016). Serotonin modulates glutamatergic transmission to neurons in the lateral habenula. Sci. Rep. 6:23798. doi: 10.1038/srep23798
Zhang, L., Hernández, V. S., Vázquez-Juárez, E., Chay, F. K., and Barrio, R. A. (2016). Thirst is associated with suppression of habenula output and active stress coping: is there a role for a non-canonical vasopressin-glutamate pathway. Front. Neural Circuits 10:13. doi: 10.3389/fncir.2016.00013

Zuo, W., Zhang, Y., Xie, G., Gregor, D., Bekker, A., and Ye, J. H. (2016). Serotonin stimulates lateral habenula via activation of the post-synaptic serotonin $2 / 3$ receptors and transient receptor potential channels. Neuropharmacology 101, 449-459. doi: 10.1016/j.neuropharm.2015.10.012

Conflict of Interest Statement: The authors declare that the research was conducted in the absence of any commercial or financial relationships that could be construed as a potential conflict of interest.

Copyright (C) 2016 Tchenio, Valentinova and Mameli. This is an open-access article distributed under the terms of the Creative Commons Attribution License (CC BY). The use, distribution and reproduction in other forums is permitted, provided the original author(s) or licensor are credited and that the original publication in this journal is cited, in accordance with accepted academic practice. No use, distribution or reproduction is permitted which does not comply with these terms. 